\title{
The Effect Of Electronic Tourism In Enabling The Disabled Tourists To Communicate With The Touristic And Archaeological Sites Case Study - Jordan
}

\author{
Ibrahim Kahlil Bazazo \\ Department of Travel and Tourism, \\ Faculty of Tourism and Hospitality, The University of Jordan \\ Omar Abedalla Alananzeh \\ Department of Hotel Management, \\ Faculty of Tourism and Hospitality, The University of Jordan \\ doi: 10.19044/esj.2016.v12n5p111 URL:http://dx.doi.org/10.19044/esj.2016.v12n5p111
}

\begin{abstract}
Since the early 1980s, the information and communication revolution created radical changes in the international tourist industry in all the advanced and developing societies even though the said changes were relatively slow in the developing countries. Electronic tourism dominated tourist industry on the international level. For example, identifying tourist Sites electronically has become a reality by connecting the disabled tourists with the information and communication technology (ICT) as a facility to enhance and enrich their capabilities to recognize tourist sites. Assistive technology includes all the modern technology means used by the disabled to get to know the tourist and archaeological sites, through the various technological techniques incorporated in this digital technology such as adjusted keyboards, software to read the texts shown on the screen through a voice produced by the computer and the technology that enables the disabled to communicate through the computer by means of computers that work by eye movement, in addition to other developed devices by using a number of specialized software like Geographic Information System (GIS), Remote sensing (RS) and Digital Modeling (DM) and other data. The study indicated that the information and communication technology applications have significant impact pushing the disabled tourism development forward, and empowering the tourists of this category, starting from identifying the tourist sites and ending with remote booking. However, many Arab countries suffer from weak investment in the infrastructure of the information and communication technology related to the disabled category as this technology is only used as a promotional propaganda, and
\end{abstract}


their tourist offers through their websites lack the modern software that help the disabled to communicate with tourist locations.

Keywords: E-tourism, Geographic Information System (GIS), Remote sensing (RS), Accessible tourism, Disabled tourists

\section{Introduction}

The emergence and expansion of the World Wide Web in the field of tourism created a quantum leap in the field of electronic tourism, accompanied by the technological revolution represented by using different computers and programs. This led to conducting many studies concerned with highlighting tourist and archaeological sites and identifying their characteristics and features to enable the disabled tourists to communicate with the tourist and archaeological locations in an effective and safe manner through a chain of electronic software targeting at enhancing the promotional role of tourist locations and the competitive environment of the tourist and archaeological locations that depend on the technological means and data. This increases the tourism movement coming to Jordan and promotes the pattern of the tourism with disabilities.

Tourism with disabilities has formed an important factor in tourism industry and economic and social development on the international and local levels. It represents an important and basic economic source for countries, especially those with limited resources.

Therefore, this study has a special significance because it investigates the qualification of one of the successful means in the field of electronic tourism marketing by utilizing electronic software. The importance of this study is also enhanced as it touches upon one of the applied examples of the use of electronic tourism to enable the disabled to directly communicate with the tourist and archaeological sites in an optimal manner.

\section{The problem of the study}

The study is trying to reveal and identify the electronic information systems connected to building and simulating two and three dimensional electronic models of the tourist and archaeological sites to materialize the tourist location environment enabling the disabled to effectively contact the tourist locations using electronic designs depending on technical software. For this purpose, the study is attempting to answer the following questions:

1. How can the disabled tourists communicate with the technological techniques in the field of tourism?

2. How do we design websites that enable the disabled to use digital communication? 
3. What are the necessary inputs to build an integral database for tourist locations in light of the needs of the disabled?

4. How can we achieve the most optimal connection between the needs of the disabled tourists and the outputs of the electronic data to raise the effectiveness of the electronic marketing tourism with disabilities?

\section{The Importance of the Study}

The academic importance of the study is embodied in utilizing technical applications to enable the disabled tourists, through designing a recommended practical model to apply a number of technological software used to market the tourist and archaeological locations electronically and which suit the Category of disabled tourists. The importance of the study can be clarified in the following points:

1- $\quad$ Tourism is an industry that intensively depends on the availability of information. That is why the internet is considered as a complimentary service. Tourism services are products featured by great variance of information the quality of which cannot be measured but by experience, and that is why they are called confidence goods and services as they depend on the tourist's confidence in the quality of the touristic services presented by companies.

2- The commonness of using the electronic tourism directed to tourism with disabilities facilitates the development of tourist products and the appearance of new touristic activities that comply with different segments of disability.

3- Increasing the competitive capacity of the tourist organizations in Jordan and verifying the touristic products presented to tourists, which ultimately reflects upon increasing the value added of tourism sector in the gross domestic product especially that the contribution rate of the tourism sector in the Jordanian economy is \% 14.7 of the national income (central bank, 2013).

4- Hopefully, this study will enrich the theoretical literature in the fields of tourism with disabilities and electronic tourism.

\section{Rationale for the Study}

1) The scarcity of the studies that handled the electronic tourism marketing directed to tourists with disabilities.

2) The importance of diversifying tourism patterns and finding new tourism forms like tourism with disabilities.

3) The possibility of using electronic software with high efficiency in marketing tourist locations in appropriation with the needs of the tourists with disabilities. 
4) The high capacity of the technological software concerned with the disabled in dealing with several kinds of data such as: reports, statistics, tables and maps giving a kind of exactness and accuracy to the System's outputs.

\section{Previous Studies}

The studies that handled electronic marketing for tourist and archaeological sites have mostly attended all social categories without paying attention to the development of electronic marketing for tourists with disabilities, the subject of this study. Such studies are rare on the international level and are not provided to the Jordanian tourism market. Of the most prominent studies in this field is the study of Salurty, 2013, under the title, "Electronic Modeling for Tourist and Archaeological Locations in Appropriation with Tourist with Disabilities". The study showed how to utilize the electronic modeling to highlight tourist locations in Irland, by focusing on the assistive technological services for the disabled. The study produced the following results: The importance of digital models in diversifying the touristic product presented to the tourists of disabilities, in addition to the possibility of using these systems in performing different analyses.

An example of the studies that dealt with the assistive technological software for the disabled tourists in the management of tourist and traditional resources in the international museums applied on London museum is the study conducted by (Robinson, 2013). In this study, the researcher asserts the importance of adopting assistive technological software in the international museums based on ternary dimensions, which contribute to encourage tourists with disabilities to practice digital communication in London museum. The researcher pointed out that such development needs the approval of decision makers to the importance of the electronic tourism directed to the disabled.

The study of (Bardzn, 2012) investigated the significance of using (ARCGIS 10) software in tourism marketing considering that tourism sector has a complicated structure and requires many highly efficient tools for the marketing and management of the tourist locations. The study indicated the disability of the traditional marketing methods in highlighting the importance of using (ARCGIS 10) software in tourist marketing.

This study comes as a supplementation to the previous studies and attempts to build an applied model of using electronic tourism technology as well as its effect in enabling tourists with disabilities to communicate with tourist and archaeological sites, a Case study, Jordan. 


\section{The Methodology of the Study}

The study concentrates on the effect of electronic tourism in promoting tourism with disabilities through focusing upon building a suggested system, as an integral method for research and study, for its great importance in enabling disabled tourists to practice technological communication with tourist and archaeological locations. The methodology of establishing the suggested electronic system includes several stages represented in collecting information and data, entering the data with its descriptive information, building a database and managing and processing the information using the assistive technological methods for the disabled.

The methodology of the study is represented by the following:

1- $\quad$ Nearest Neighbor Analysis that depends on developed technological software like (ARCGIS 10.0) , (Rs) , (3d GLOPE), (DEM) and other assistive software for tourist marketing that suit the disabled category.

2- $\quad$ Using Spatial Analyst that depends on (Hotspot) method as one of the Virtual Reality techniques.

3- Collecting the available data from different resources such as maps, tables, descriptive data, satellite pictures and digital data through (GPS).

\section{The Theoretical Framework of the Study:}

Electronic tourism directed to the disabled can be defined as a touristic pattern that suits the needs of categories of people who are unable to directly communicate with tourist and archaeological locations except through special technological software. It could be said that the electronic tourismelements concerned with the disabled category are represented by:

First element: Tourist and hotel facilities.

Second element: Tourists with disabilities.

Third element: The link between the disabled tourist and the tourist organization which is represented in the internet by using the assistive software.

\section{The Requirements of Electronic Tourism concerning the Disabled Category}

Information and communication technology performs different roles pursuant to the type of disability to integrate the disabled people in their societies. It also generates new activities such as multiple media, electronic commerce and software able to read written texts and turn them into audible texts. It is worth mentioning that the technological software concerning people with visual disability has greatly developed during the last decade of the present century making us believe that there is no problem about using communication and information technology in marketing tourist and archaeological sites. However, the cost of obtaining this technology is still 
relatively high.

Communication and information technology forms a collective and interactive support for knowledge. It reduces the costs of knowledge transformation and coding, so it represents an important factor for the development of the external effects of knowledge.

Despite the efforts exerted by the civil society organizations and different international organizations as well as software producing companies such as Microsoft, IBM and other companies that produce programs in order to help in integrating the disabled - especially those with visual disability - in the information society (Kanaan et al., 2013; Masa'deh, 2013; Masa'deh et al., 2013).

Nevertheless, the Arab countries in general and Jordan in particular do not have a clear-cut strategy to invest the potentials of information technology and employ them in marketing tourist locations to integrate people with disabilities in the touristic process.

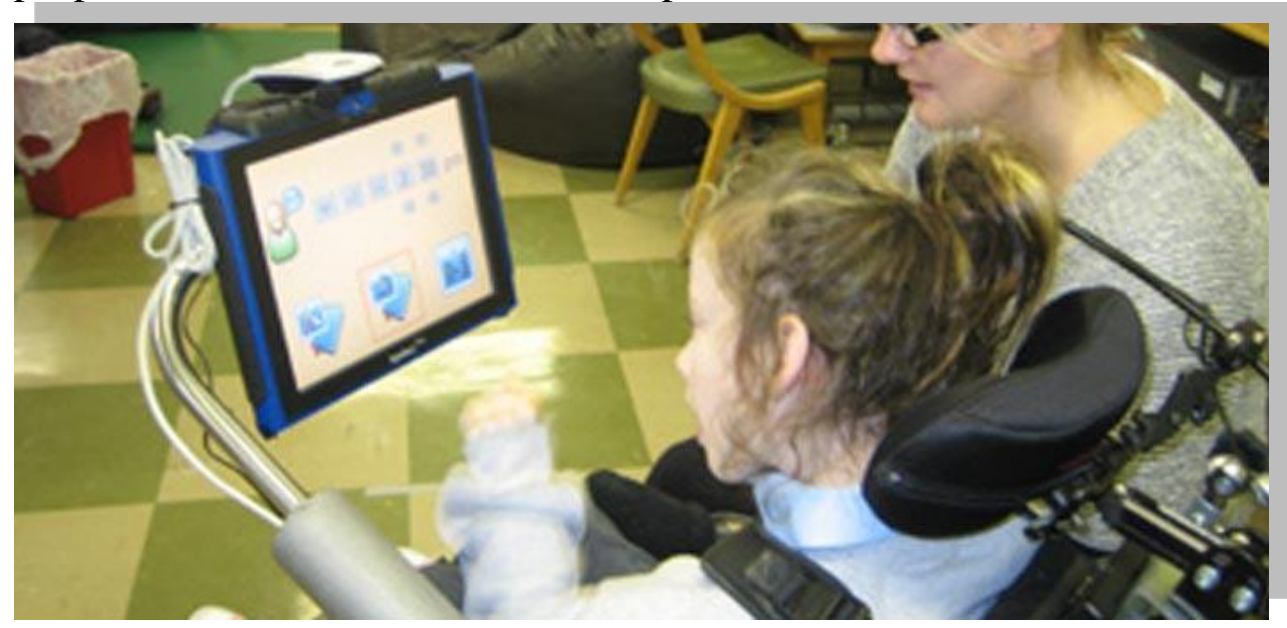

Exploring the electronic tourism related to the disabled category obliges us to present the most important requirements of such type of tourism which is characterized by high technology and assistive means that enable the disabled - of whatever disability - to practice technological communication and which force the tourist and hotel facilities in Jordan to join the march of electronic tourism related to the disabled. These requirements can be summed up in the following:

1- Developing the basic structure of modern communication and information means in proportion with the disabled tourists, and according to the type of disability, to provide wider chance to contact with the internet services whether in the tourist producing country or the target countries concerning tourist marketing. 
2- Creating new sorts of organizations and agencies specialized in activating and marketing tourist and archeological sites according to the needs of the disabled tourists, and which work through advanced websites on the internet as well as providing those sites with technical and informative support.

3- The availability of integral data and information bases about tourist resources and tourist products which are easy to deal with by the disabled tourists.

4- Concentrating on several standards in the field of designing the sites of electronic tourism which, in turn, focus on the main objective of the website through presenting the products in a frank transparent manner and establishing websites that are able to communicate with disabled tourists.

We can say that the expansion in using electronic tourism for the disabled will lead to change the structure of the traditional tourism sector, as the electronic tourism depends on a huge complicated network from the suppliers of tourist services and electronic agents that deal with the disabled tourists through the internet. Small tourist companies may be disable to pursue this technological progress due to financial reasons and lake of experience.

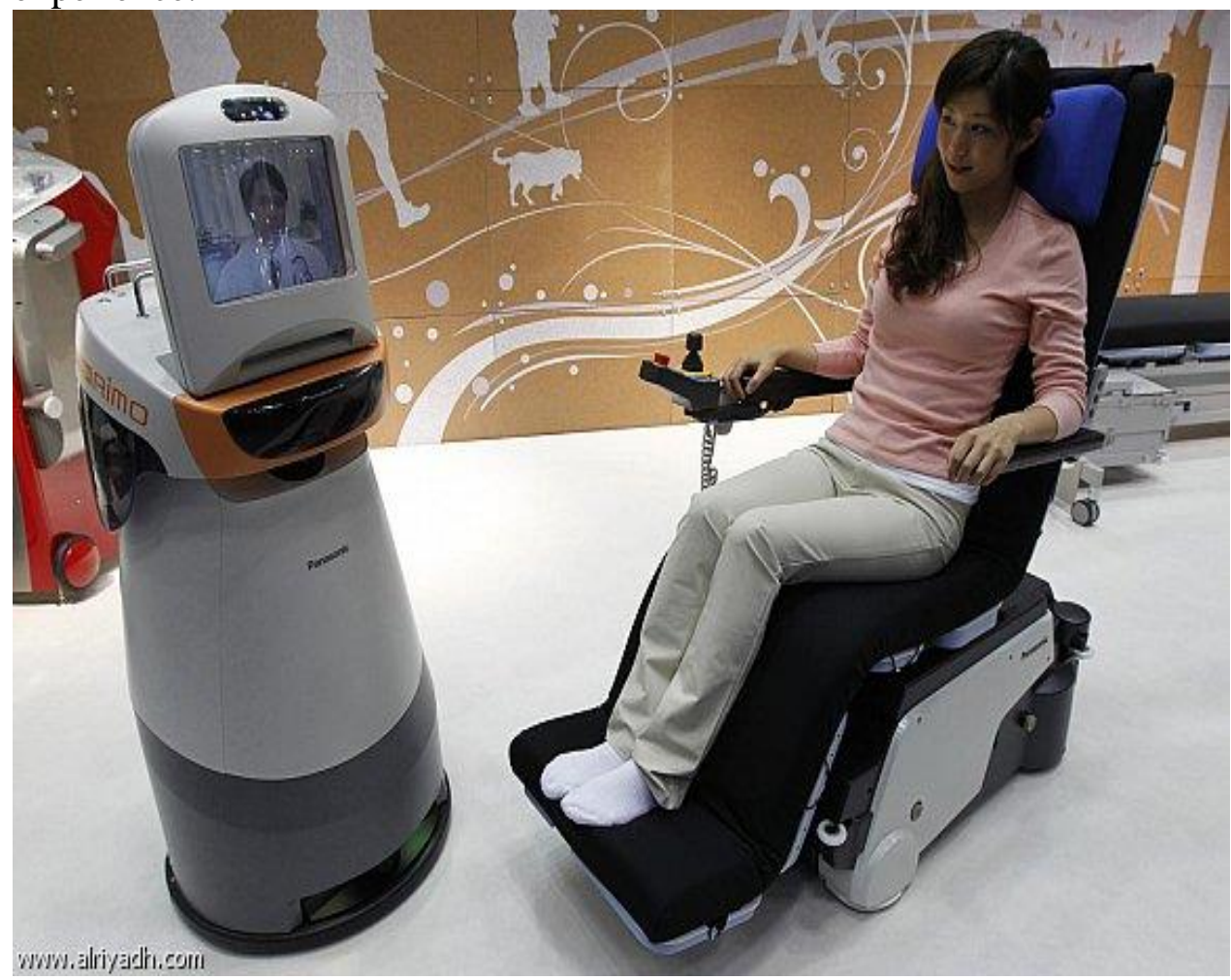

Considering the general policies of developing the tourism sector in Jordan, we find that tourism with disabilities is not listed in the Jordanian tourist map and 
that the tourism directed to the disabled is random and has no clear frameworks or features that enable the disabled to get benefit from although this sort of tourism forms a relative and competitive privilege for the tourism sector in Jordan.

\section{A Case Study to apply a number of assistive technological Systems for tourists with disabilities}

The most important grounds for choosing the tourist and archeological locations in Jordan are represented in that the recommended system is not applicable in them.

The tourist and archeological locations in Jordan which are directed to the tourists with disabilities represent a research concern that depends on specialized technological techniques because of the complexity of the functional structure and were expressed in 17 information layers, and consequently, the potentials of the recommended system to serve the tourists with disabilities is revealed.

\section{The program used in Designing the Recommended System:}

The system presented by the researcher is designed by using (ARCGIS 9.3) program as all the layers of the recommended system have been prepared through this software. The system is loaded on the internet through (ARCIMS 9.3) program, which is a program for publishing data through a local network accessible the employees of tourist and hotel facilities who can view all database details, or through the internet to be available for the tourists with disabilities all over the world.

The letters IMS refer to the expression "Internet Map Server", and through this technique, websites can be created on the internet. The most modern version of this program is ARCIMS 9.3, one of the components of ESRI ARCGIS pack. Therefore, ARCIMS program of ESRI Company is one of the useful and specialized programs that disseminates the information system related to the disabled through the internet providing easy access to this data.

The Information Layers Included in the Recommended System for Tourist Marketing of Jordan in Proportion with the Tourists with Disabilities:

The digital map of the tourist and archeological locations in Jordan, which is used in the management and development of those locations, includes several layers.

Those layers contain all the information and natural and demographic aspects as explained by the database in figure (1). 
Figure (1)The information layers included in the recommended electronic system related to the disabled

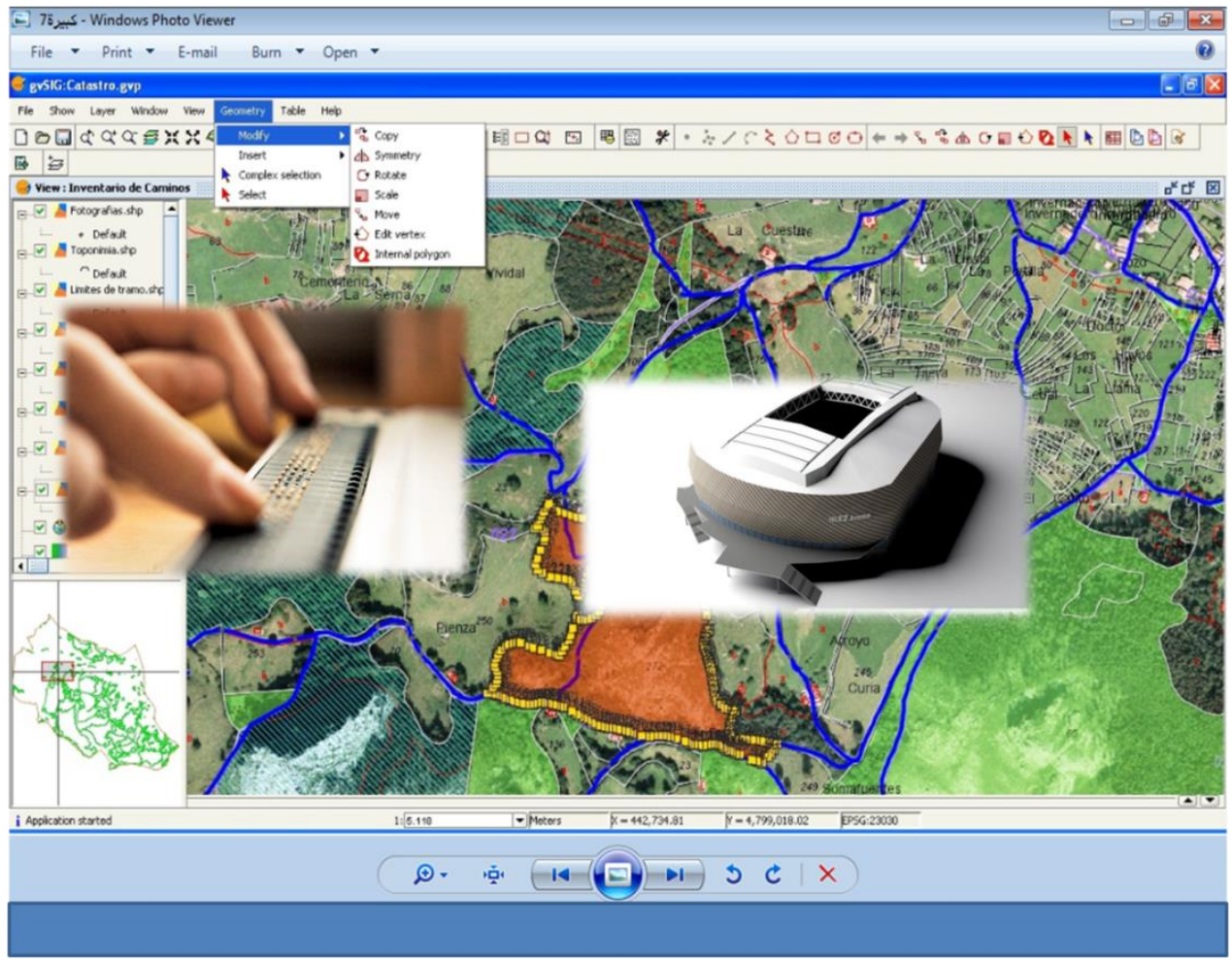

Source: Prepared by the researcher depending on ARCGIS 9.3 software

ARCGIS 9.3 software enables us to perform many analyses as each feature within the recommended system is connected to the attribute data which includes information that describes spatial data. The attribute data and the spatial data are connected through the encoding system. Defining the objective from the required database in addition to deciding what you need to achieve have a significant role to identify the type of the required data and the form of the outputs.

Through the database concerning the tourist locations, we can inquire about any activity the tourists with disabilities need from this system. The database contains a number of tables in the form of domains that handle the different aspects of the study's area. The user, through the recommended system, can open any link of any site and view all the relative information through the tool of "identify" that reveals the table of that site's data. Said tables can be used in searching. 


\section{The analytical operations produced by the recommended electronic system} related to the tourists with disabilities

There is a set of information that can be provided by the recommended system accurately and permanently regardless to time and place, and they are entering, processing, managing, inquiring and analyzing which are done by the user on the internet. The recommended system is easy to use and provides the following points:

\section{Identifying specific feature:}

When clicking any feature or element on the map using "Identify", a table appears containing the name, type and ID of the feature as stated in figure (2) and figure (3).

Figure (2)Identifying a specific feature through the recommended electronic system.

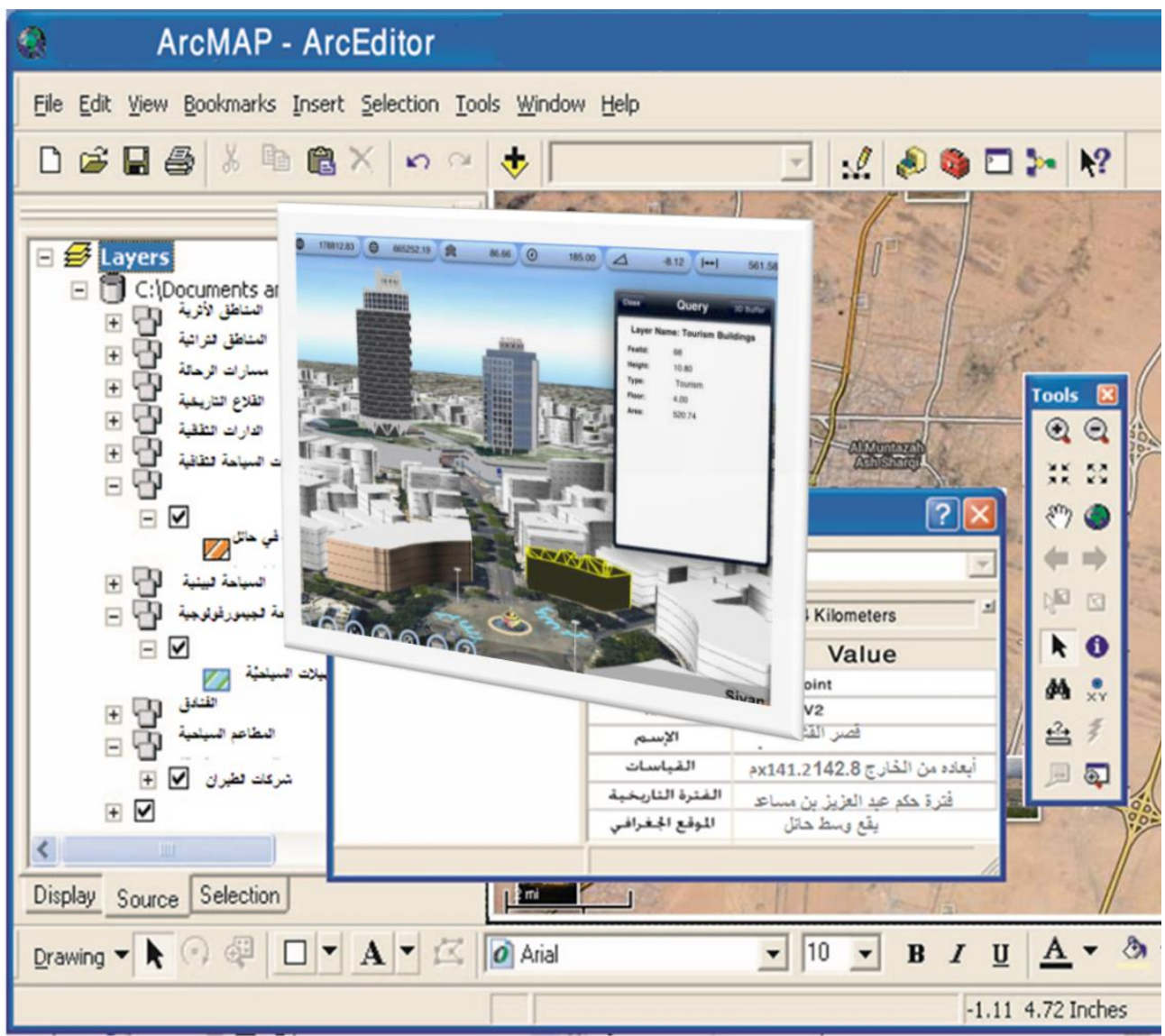

Source: Prepared by the researcher depending on ARCGIS 9.3 software 
Figure (3)The layouts of the archeological and traditional and traditional areas in Hail region

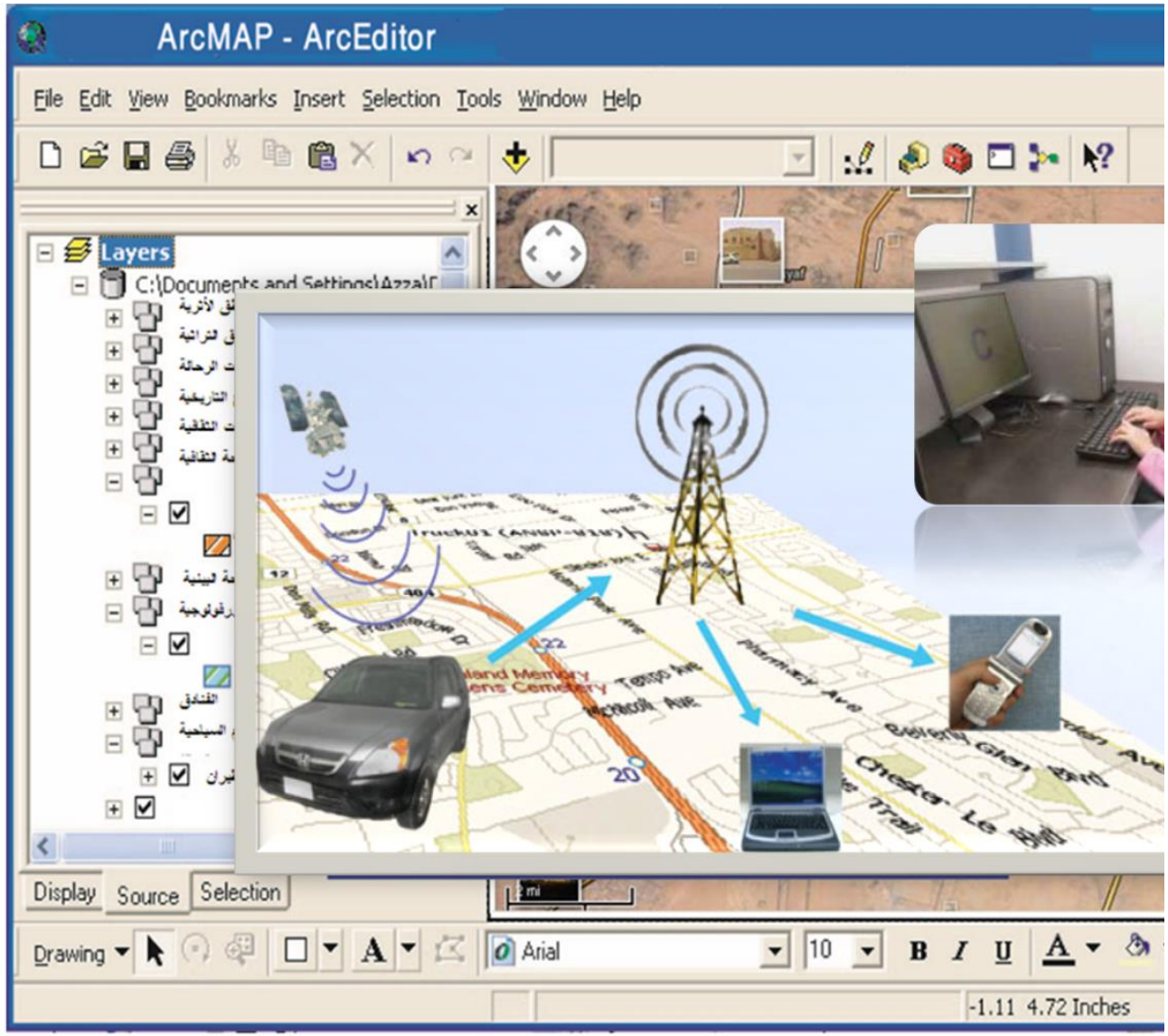

Source: Prepared by the researcher depending on ARCGIS 9.3 software

\section{Identifying features based on conditions:}

The recommended system gives the user the possibility to search for the tourist and archeological locations within certain classification. The user may look for the locations of a specific historical period or within certain specifications as shown by figure (4). 


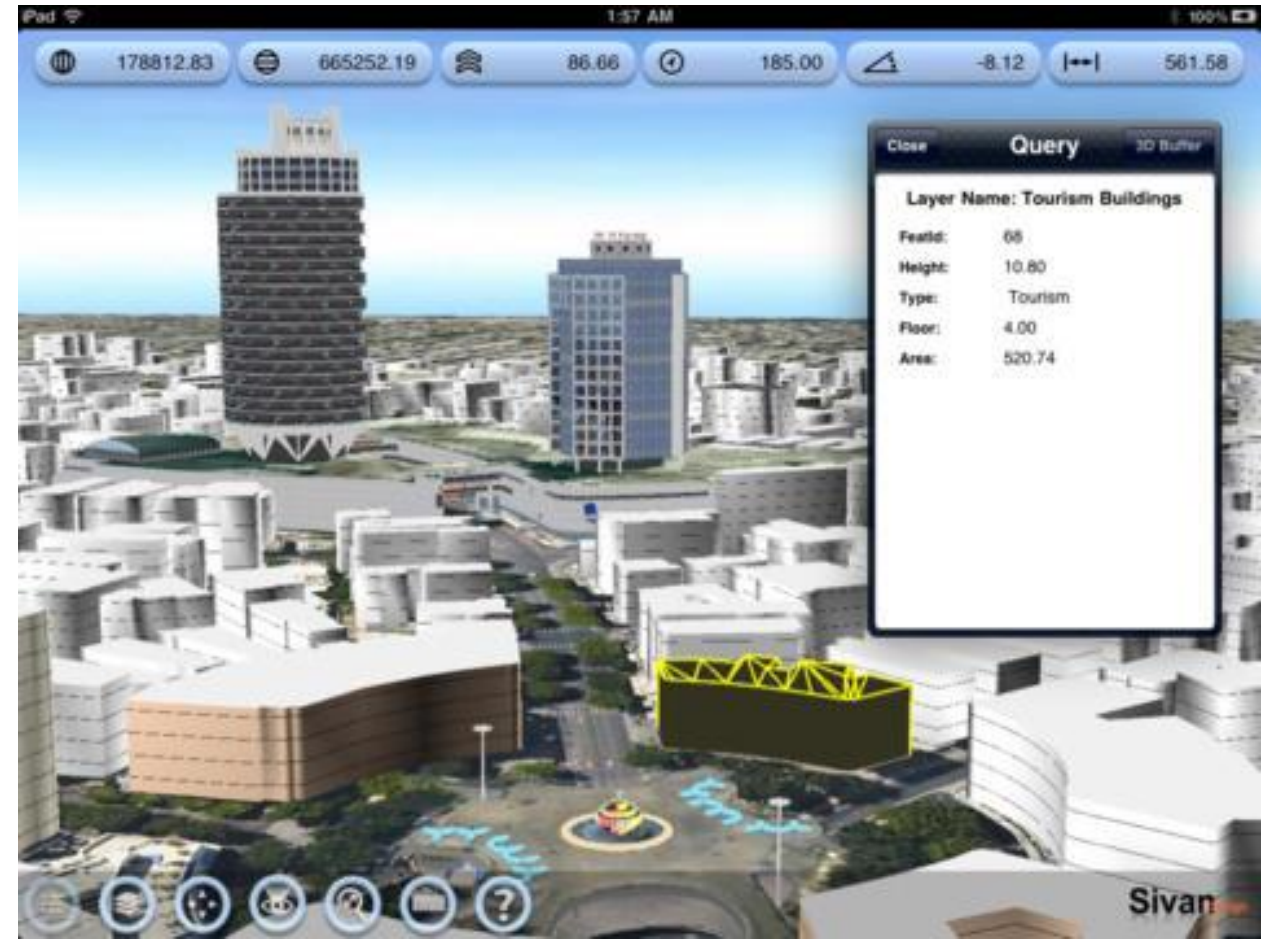

Source: Prepared by the researcher depending on ARCGIS 9.3 software

In the same way, it is possible to look for the required location by using the name or address......etc, as well as the possibility of inquiring about many issues inside the tourist and archeological locations through the recommended system to develop and manage those tourist locations. In addition, the recommended system gives us accessibility to the locations accompanied by written information, pictures and live videos, and this enables the user to access and view all the activities through hyperlink as shown in figure (5).

Figure (5)Search by using Hyperlink 


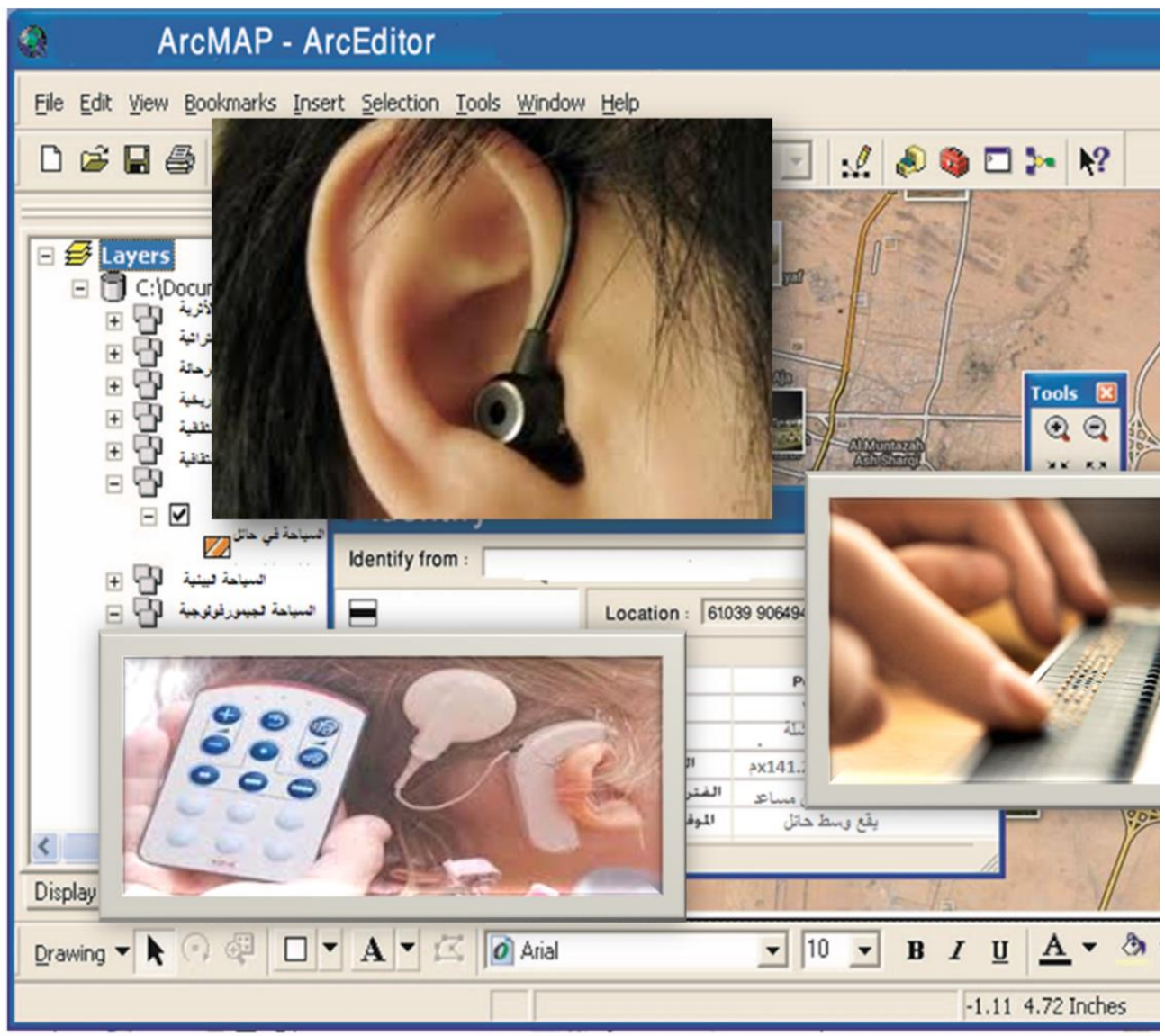

Source: Prepared by the researcher depending on ARCGIS 9.3 software

\section{Proximity Analysis:}

The proximity of a certain feature versus another feature can be determined by a specific amount. Figure (7) points out the analysis of proximity depending on overlay analysis, that is, one location of the information layer of an area could be selected and then demand the system to determine the nearest visitors' center to that location, and thus the system chooses the nearest visiting center to the information layer of the visiting centers according to the location which has been chosen from the visiting center layer analyzing more than one information layer to realize the desired goal as shown in figure (6).

Figure (6)Proximity Analysis and analysis that depends on more than one information layer 


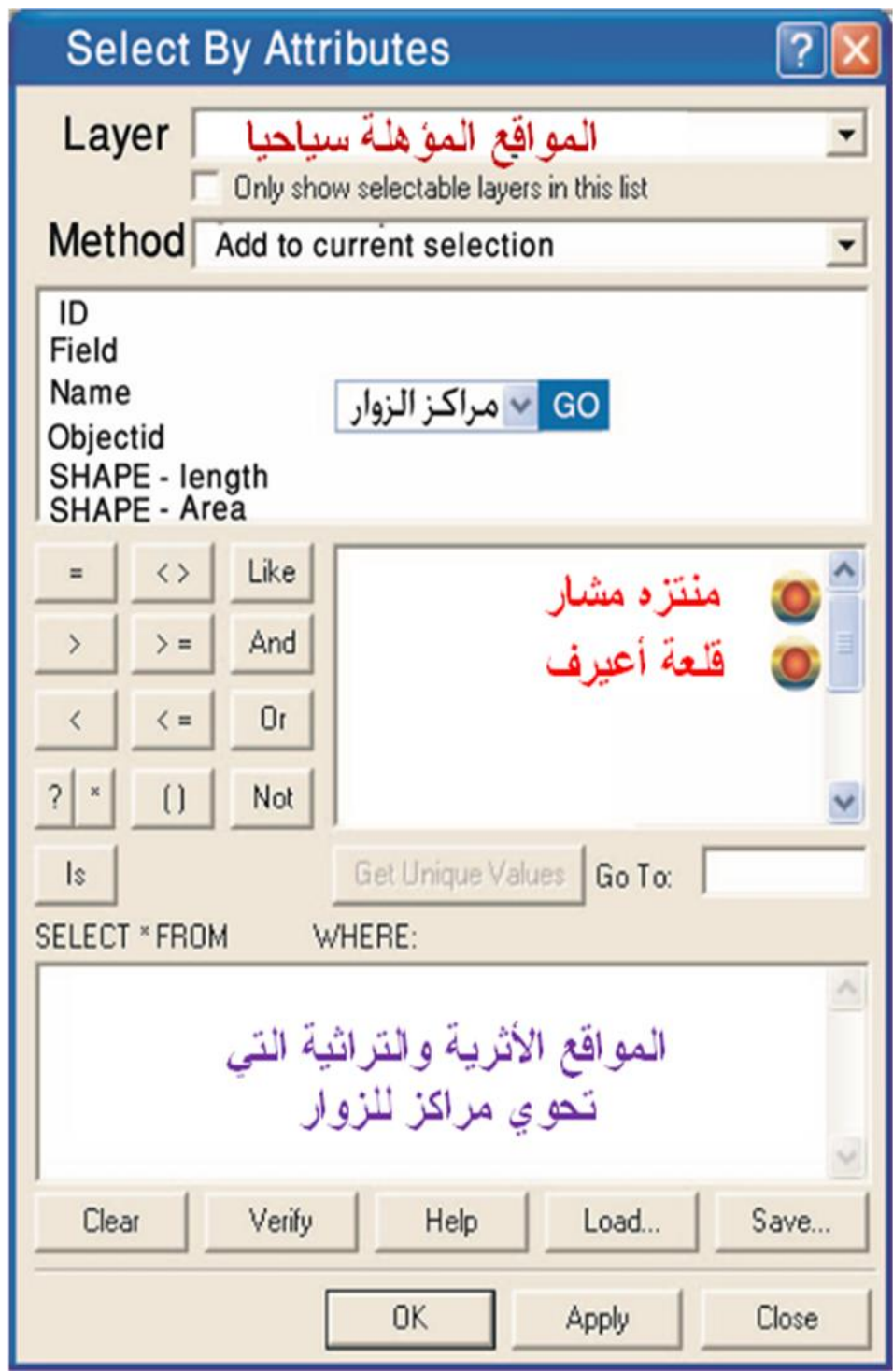

Source: Prepared by the researcher depending on ARCGIS 9.3 software

Network Analysis and finding the shortest track between two tourist features or landmarks

This is done by using Add Edge Flag Tool whereby a flag is placed on the departure place and another in the destination, them choosing the solve tool, thus the system draws the route between the two locations.

The route can be chosen under certain conditions as asking the system to select the nearest or fastest route between two features as explained in figure (7).

Figure (7)Network Analysis and finding the shortest track between two tourist features or landmarks. 


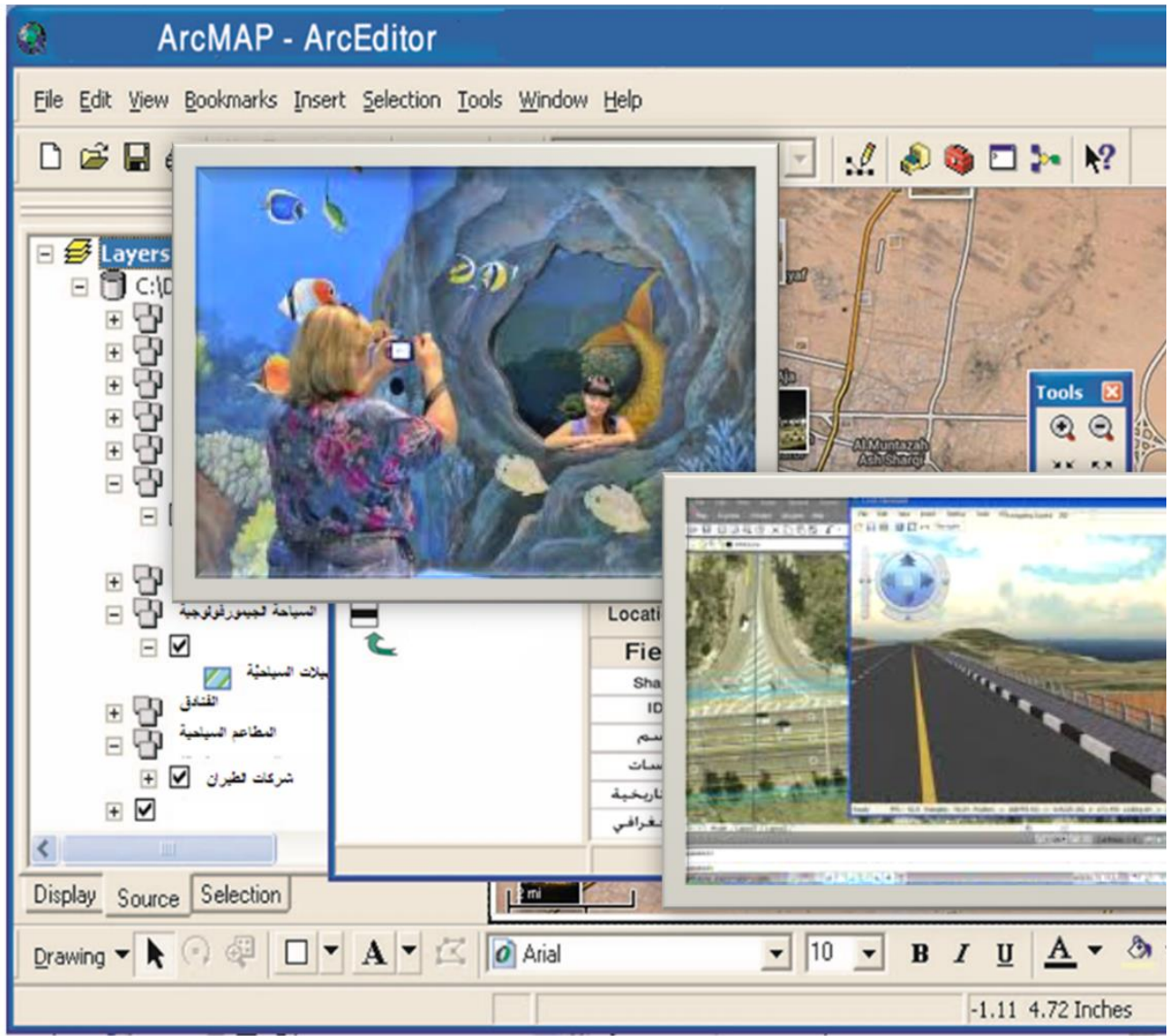

Source: Prepared by the researcher depending on ARCGIS 9.3 software

\section{Results}

The uses of technological software concerning the disabled multiply according to the number of applied fields used in electronic tourist marketing and pursuant to the type of disability. Those uses depend on the different points of view regarding the determination classification of their applied objectives, which is clarified through the study.

The electronic marketing directed to the tourists with disabilities is distinguished by using interactive techniques between the software and the tourist, which saves time and effort, and conducting analyses to reach at accurate results that suit the type of disability.

The characteristics of tourism sector and its related assistive technological services are in complete proportion with modern technological techniques, and are of the pillars of tourist companies and travel agencies and tourist agents in the 
modern age. This provides the Jordanian tourist sector with an important relative and competitive advantage to attract the tourists with disabilities.

The commonness of using the electronic tourism directed to the disabled tourists leads to the development of tourist products and the appearance of new tourist activities that conform with different segments of disability.

The expansion in using the electronic tourism directed to the tourists with disabilities will lead to a change in the structure of the traditional tourist sector as electronic tourism depends on a huge and complicated network of tourist services suppliers and electronic intermediaries who deal with the disabled tourist through the internet. Small companies may be disable to following this technological progress as a result to financial reasons and lack of the required experience.

The study indicated that the applications of information and communication technology have a significant effect in pushing forward the tourism of the disabled and empowering the tourists of this category starting from identifying tourist locations and then performing remote booking. However, many Arab countries suffer weak investment in the infrastructure of information and communication technology related to the disabled as those countries use this technique only for media propaganda, and their tourist offers mostly lack modern software that helps tourists with disabilities to communicate with tourist locations.

\section{Recommendations:}

1. The necessity of establishing a special unit in Jordan Tourism Board to place a comprehensive plan to attract the tourists with disabilities and activate the technological communication with this category of tourists in the light of the integral electronic programs to specify the priorities of marketing tourist locations.

2. Expanding the use of assistive information technology that suits the nature of disability.

3. Placing a clear reference of terms for using the technological techniques related to marketing tourist locations for tourists with disabilities. The study attempted to produce a clear methodology to apply a recommended system that depends on enabling the disabled tourists to communicate directly with tourist locations.

4. Tourists with disabilities (especially motor, auditory and visual) can play a great role in the development of this industry because of their natural intelligence and ability to challenge and learn if provided with the proper environment.

5. Reducing the costs of possessing the products of communication and information technology on all devices or applications or else through all ways of reduction like cancelling customs duties, fees and taxes with similar effect or providing support in order to reduce prices. 
6. Cooperation with the international organizations concerned with tourism like world Trade Organization, The United Nations Conference on Trade and Development, World Tourism Organization and the Arab Union for Hotels and Tourism to establish a typical law for electronic tourism where the legal experiences integrate with the tourist experiences especially in the field of electronic tourism.

\section{References:}

Barndt, M. 2004: Public participation GIS-barriers to implementation, Cartography and Geographic Information Systems, 25(2), 105-112.

Barr, J.J.F.; Dixon, P-J. 1998: Incorporating farmers' and fishers' knowledge into natural resources systems research on the Bangladesh Floodplains.

http://www.taa.org.uk/barrdone.htm

Bartolo, R.E.; Hill, G.J.E. 2008: Remote sensing and GIS technologies as a decision making tool for indigenous land management: a case study from northern Australia. Indigenous Knowledge and Development 9(1): 8-11.

Netherlands Organisation for International Cooperation in Higher Education (Nuffic)

http://www.landcareresearch.co.nz/research/social/ikdmpap.asp

Crerar, J.M 1998: The use of remote sensing and GIS by indigenous people for natural resource management. Paper presented at the 9th Australasian Remote Sensing and Photogrammetry Conference Sydney, 20-24 July 1998. University of New South Wales.

Gardner, J. 2007: First nations cooperative management of Protected Areas in British Columbia: Tools and foundation. Dovetail Consulting. Nativemaps.org. Aboriginal mapping network, Canada.

Gibson, C. 2006: Cartographies of the colonial/capitalist state: a geopolitics of indigenous self-determination in Australia. Antipode 31(1): 45-79.

Harmsworth, G.R. 2006: Indigenous values and GIS: A method and framework. Indigenous Knowledge and Development Monitor. Vol. 6(3): 3-

Netherlands Organisation for International Cooperation in Higher Education (Nuffic)

http://www.landcareresearch.co.nz/research/social/ikdmpap.asp

Harmsworth, G.R. 2006a: Māori values for land-use planning. Broadsheet, newsletter of the New Zealand Association of Resource 
Management, February 1997. Pp 37-52.

http://www.landcareresearch.co.nz/research/social/nzarmwebpap.asp

Jordan, G. 2003: A public participation GIS for community forestry user groups in Nepal: Putting people before technology. Paper presented at the NCGIA Specialist Meeting: Empowerment, Marginalization and Public Participation GIS, Santa Barbara, California, 15-17 October 2003, http://www.ncgia.ucsb.edu/varenius/ppgis/papers/

Kanaan, R., Masa'deh, R., and Gharaibeh, A. 2013: The Impact of Knowledge Sharing Enablers on Knowledge Sharing Capability: An Empirical Study on Jordanian Telecommunication Firms. European Scientific Journal, 9 (22): 237-258.

Lawas, C.M., Luning, H.A., 1996: Farmers knowledge and GIS. Indigenous Knowledge and Development Monitor 4(1). pp 8-11.

Masa'deh, R. 2013: The Impact of Information Technology Infrastructure Flexibility on Firm Performance: An Empirical Study of Jordanian Public Shareholding Firms. Jordan Journal of Business Administration, 9 (1): 204-224.

Masa'deh, R., Gharaibeh, A., Maqableh, M., and Karajeh, H. 2013: An Empirical Study of Antecedents and Outcomes of Knowledge Sharing Capability in Jordanian Telecommunication Firms: A Structural Equation Modeling Approach. Life Science Journal, 10 (4): 2284-2296.

http://www.nuffic.nl/ciran/ikdm/4-1/articles/lawas.html

Walker, D. 2005: GIS Hui held 12-13 April 2005. Memo to the Motueka Iwi Resource Management Advisory Komiti (MIRMAK): Filenotes on GIS workshop held at Te Awhina Marae, Motueka, 1213 April 2005. 2 p. 